\title{
SÍNODO EXTRAORDINARIO SOBRE «LOS DESAFÍOS PASTORALES DE LA FAMILIA EN EL CONTEXTO DE LA EVANGELIZACIÓN» Reflexiones desde una parroquia
}

DOI: https://doi.org/10.52039/seminarios.v60i212.198

ALFONSO CRESPO*

Nunca un Sínodo de los Obispos había suscitado tanto interés ni había sido objeto de comentarios a pie de calle. Noticias simplistas pero cargadas de intención o coloquios en el autobús faltos de información, han sido temas recurrentes en las tertulias y han ocupado portadas de periódicos: «La Iglesia admite a los gay»; "se reconocen otros tipos de unión»; "¿pueden comulgar los divorciados vueltos a casar?». Y, desde los círculos más eclesiásticos, un maniqueísmo soterrado: ¿se impone la línea dura en el episcopado? ¿Se acosa la línea aperturista del papa Francisco? Y el titular de prensa: «Lucha entre las dos corrientes en el Sínodo».

Y todo esto, visto desde una cierta distancia y, por lo regular, con una escasa información. Podríamos decir que, por primera vez, ha habido -fuera del aula sinodal- miles de "padres sinodales» opinando sobre el tema, haciendo «círculos menores de opinión» y adelantando conclusiones favorables al propio pensamiento.

La información suministrada por la Sala de Prensa del Vaticano ha sido abundante (excesiva, según algunos; controlada, para otros). Y una novedad: el Papa ha permitido que se publiquen las conclusiones de la Relación Final (Relatio Synodi), incluidas las votaciones de cada una de las propuestas.

Esta reflexión, como subrayo en el subtítulo, es simplemente una humilde reflexión hecha desde una parroquia y por quien toca diariamente la problemática matrimonial y familiar. Tiene dos partes: en la primera, hago una relectura del Sínodo desde sus diversos documentos; en la segunda, sugiero varias vías de reflexión para enriquecer unas posibles respuestas pastorales que dinamicen la pastoral misionera de la parroquia.

* Alfonso Crespo Hidalgo es profesor de teología y actualmente también párroco de la Parroquia de San Pedro, en Málaga. 


\section{El Sínodo celebrado}

\section{Naturaleza, fines y limitaciones del Sínodo}

El Código de Derecho Canónico, en el canon 342, define la naturaleza del Sínodo: «El Sínodo de los Obispos es una asamblea de Obispos escogidos de las distintas regiones del mundo, que se reúnen en ocasiones determinadas para fomentar la unión estrecha entre el Romano Pontífice y los Obispos, y ayudar al Papa con sus consejos para la integridad y mejora de la fe y costumbres y la conservación y fortalecimiento de la disciplina eclesiástica, y estudiar las cuestiones que se refieren a la acción de la Iglesia en el mundo».

Es el Papa quien convoca el Sínodo. En el decreto de convocatoria, el Papa especifica el tipo de Asamblea y el tema a tratar, y designa a los miembros del Sínodo, nombrando entre ellos la Secretaría General, a la que se le encarga elaborar un Documento de Trabajo (Instrumentum laboris) que se envía a las Conferencias episcopales, y otras personas expertas. En él se contienen las líneas generales de los temas que tratar en la Asamblea, así como las consultas que se estimen oportunas. En concreto, con motivo de este Sínodo, ha querido el Papa ampliar la consulta a todo el pueblo de Dios, recibiéndose múltiples respuestas en la Secretaría del Sínodo y en las distintas Conferencias Episcopales.

La Asamblea del Sínodo de los Obispos se desarrolla en Roma, aunque nada impide que tenga lugar en otro sitio. Las Asambleas pueden ser Extraordinarias (una significativa fue la celebrada en 1985 para celebrar los veinte años de la clausura del Concilio; la recientemente celebrada, ha sido la Tercera Extraordinaria) y Ordinarias (la próxima será la XIV). Suelen desarrollarse en sesiones diarias durante un mes aproximadamente. Se han celebrado también Sínodos Especiales, en concreto sobre las Iglesias de los diversos continentes. Dentro del mecanismo de su funcionamiento, se pueden distinguir estos pasos:

-Se inicia, después de una concelebración solemne presidida por el Papa, con una Primera Relación (Relatio ante Disceptacionem), en la que el Secretario de la Asamblea (en ésta ha sido el húngaro el Cardenal Peter Erdó, arzobispo de Esztergom-Dudapest) presenta una síntesis del sentir general de las respuestas recibidas al Instrumentum laboris.

-Siguen las sesiones en el aula sinodal, en las que todos los participantes en el Sínodo tienen unos minutos para tratar sobre el tema en general o algún punto específico. El Papa suele asistir a todas las sesiones, en una actitud de humilde escucha.

-Concluye esta primera parte con una Segunda Relación (Relatio post Disceptacionem), que presenta el Secretario, recogiendo las aportaciones del aula sinodal, en forma de propuestas numeradas. En concreto, este documento contenía 58 números.

-Se pasa después a los llamados "círculos menores», grupos de trabajo por lenguas, que reflexionan y hacen sus aportaciones al documento precedente. 
-Todo lo anterior, lleva a una Relación Final (Relatio Synodi), en la que se recogen las propuestas finales, que son votadas por la asamblea sinodal y que son elevadas al Santo Padre. En este Sínodo han sido 62. Como novedad, el Papa ha querido que se haga público este documento y las votaciones sobre cada una de las propuestas. Podemos, pues, constatar el grado de asentimiento de los asistentes a cada una de dichas conclusiones.

Las Asambleas del Sínodo de los Obispos finalizan con la clausura, que corresponde realizar al Papa. Hasta el momento el Papa, después de casi todas las Asambleas del Sínodo de Obispos, ha promulgado una exhortación postsinodal, en la que recoge las indicaciones que considera convenientes. Exhortaciones postdinodales son por ejemplo: Envangelii nuntiandi (Pablo VI, sobre la evangelización, 1975), Catechesi tradendae (Juan Pablo II, sobre la catequesis, 1979), Familiaris consortio (Juan Pablo II, sobre la familia, 1981), Christifideles laici (Juan Pablo II, sobre los laicos, 1988) Pastores dabo vobis (Juan Pablo II, sobre el sacerdocio, 1992) y la reciente Evangelii gaudium (Francisco, sobre la nueva evangelización, 2013, que recoge el trabajo de la XIII Asamblea general Ordinaria del Sínodo). Algunos Sínodos sobre temas especiales han concluido con exhortaciones pastorales más específicas (por ejemplo, los diversos Sínodos especiales sobre los distintos continentes, entre ellos dos sobre Europa, en 1991 y 1999, con los títulos de Ecclesia in: Europa (2003), América, África, Asia, Oceanía.

Otros frutos del Sínodo han sido sugerencias concretas que se han puesto en marcha; entre ellas, hay algunas tan importantes como la elaboración del Catecismo de la Iglesia Católica, sugerencia que procede de los Padres sinodales de la Asamblea del Sínodo de 1977, que tuvo como tema la catequesis.

El Sínodo que ha concluido, como ya se ha indicado, ha sido la III Asamblea General Extraordinaria, que tendrá su continuidad en la XIV Asamblea General Ordinaria del año próximo. Será, después de ésta, cuando se recojan los frutos y, si el Papa lo estima conveniente, podamos gozar de las indicaciones doctrinales y pastorales de otra Exhortación postsinodal.

Las conclusiones de la Asamblea Extraordinaria celebrada, serán la base del Instrumentum laboris para la próxima Asamblea Ordinaria, a celebrar en 2015.

La misma naturaleza del Sínodo resalta su carácter consultivo como servicio al Magisterio; y el desarrollo de sus sesiones subraya el ejercicio de libertad y comunión necesario para dar cauces al Espíritu que, bajo el cayado de Pedro, guía la Iglesia entre «las persecuciones del mundo y los consuelos de Dios» (LG 8).

\section{2. ¿Por qué tanta inquietud antes de este Sínodo?}

La misma convocatoria de los dos Sínodos, el Extraordinario de octubre de 2014 y el Ordinario en el año siguiente, ya levantó inquietudes desde la fecha de su anuncio; incluso cierta zozobra que ha motivado un fluir de reflexiones teológicas, tomas de postura, recelos y a veces, esto es grave venga de donde venga, 
oposición con cierto menosprecio. No ha sido así en los Sínodos anteriores. ¿Por qué ahora? La causa del revuelo es quién lo convoca y la materia a tratar.

Si el Sínodo hubiera sido sobre la evangelización en general, sobre la paz en el mundo, sobre la justicia y la pobreza, no habría corrido tanta tinta y no hubiéramos asistido a debates de tanto calado teológico, expresados en diversas publicaciones. Pero convocaba un Papa con un talante y un arrojo que desconciertan. Además, tuvo la osadía de querer tomar el pulso a lo que el pueblo de Dios -una realidad teológica y no una pura variable sociológica- pensaba desde la vivencia cotidiana de la realidad de la familia y el matrimonio: sus gozos y dramas. Pedir opinión fuera del círculo de los propios allegados siempre provoca inquietud.

Algunos, también, han puesto en cuestión esta decisión del Papa de pedir una opinión general y pública, previa a la misma Asamblea. Y surge una primera reflexión: ¿pedir opinión, partir de una visión amplia de la realidad, es negativo o a lo mejor ayuda a que los documentos tengan mejor aterrizaje y recepción porque se escapan de lo puramente especulativo?

No necesitamos más documentos o libros de teología que expliciten el Magisterio, sino creatividad y atrevimiento para buscar desde la misma mirada del Magisterio «nuevas respuestas a nuevas preguntas vitales». Las respuestas tienen que salir de los invernaderos de la reflexión y de los debates especulativos de escuelas y pasar por la intemperie de la calle, para acercar la belleza de la doctrina a la sencillez del que busca respuesta, a veces angustiada, a su situación vital interpelada por una fe que se debilita. Quizás, las respuestas y el eco ocasionado por la consulta nos han puesto sobre aviso de que la parábola se ha podido invertir: se trata ya no de que noventa y nueve están en el redil, sino de que son más de una las que se han ido. Desde la pastoral de calle, no se trata de recrearnos en una pastoral que engorde a las que restan, el desafío es como rodear a las que merodean junto al redil para abrirles la puerta «con verdad y misericordia». Debemos colaborar con la gracia para forzar que el tiempo se convierta en kairós para muchas personas: Abrimos un nuevo siglo. Ahora ya sabemos que la tierra se mueve, es urgente no quedarnos mirando fijamente a la luna.

Es, con razón, este un Sínodo que «ha legitimado» su derecho a encabezar su posible Exhortación postsinodal con el título acostumbrado: «A los obispos, a los presbíteros y diáconos, a las personas consagradas y a los fieles laicos». En el fondo, la futura Exhortación será una Carta de respuesta a unas inquietudes vividas -y sufridas muchas veces- por aquellos a los que también se les pidió la opinión, y que forman parte del pueblo de Dios.

3. Una lectura entre líneas de la III Asamblea Extraordinaria del Sínodo sobre la familia

Suele ocurrir. Cuando hay un acontecimiento eclesial, sobre todo si es sobre un tema que necesita diálogo y que toca la sensibilidad social, se abren dos lecturas: la que ocurre en el aula donde se debate y la percepción periodística 
del tema. Así ha ocurrido. La Iglesia, en sus instituciones, a veces es reacia a la información. Hoy, sin una buena información, es casi imposible situarse eficaz y apaciblemente en medio del mundo. En esta ocasión, ha sido un acierto la transparencia informativa. Incluso la novedad de hacer públicas las votaciones de la Relación final. Ya sabemos dónde están los puntos de debate. Para algunos será un motivo de escándalo. Para los muchos, un acicate para seguir madurando la reflexión.

No es fácil leer entre líneas unos documentos sin haber sido oyente. Pero es legítimo exponer unas apreciaciones generales.

\section{a) Una polémica centrada en una visión parcial de los objetivos de este Sínodo}

En las discusiones previas a la celebración de la Asamblea, discusiones a veces apasionadas (lo cual no favorece ni la profundidad ni la ecuanimidad de la reflexión) el punto de debate se ha centrado en exceso, junto al tema de la homosexualidad y el parecer del Magisterio, en un aspecto concreto, ciertamente poliédrico y conflictivo pero que no constituye el principal problema de la familia cristiana hoy y que no debe centrar, en exclusividad o principalmente, el debate sinodal abierto. Se trata de los casos de «quienes recibieron el Sacramento del Matrimonio, éste se ha roto y, no encontrando remedio en el ordenamiento matrimonial canónico - no se ha declarado la nulidad- se han vuelto a casar civilmente y, conservando su fe y constituyendo una nueva familia, piden recibir la comunión eucarística».

El capítulo tercero del Instrumentum Laboris del III Sínodo Extraordinario dedicado a «Los desafíos pastorales de la familia en el contexto de la evangelización», en el que se incluyen estos temas más polémicos, se abría con estas palabras programáticas: «De las respuestas (de la consulta general previa) emerge la común consideración que, en el ámbito de lo que se pueden definir situaciones matrimoniales difíciles, se celan historias de gran sufrimiento, así como testimonios de amor sincero. 'La Iglesia está llamada a ser siempre la casa abierta del Padre [...] la casa paterna donde hay lugar para cada uno con su vida a cuestas' (EG 47). La verdadera urgencia pastoral es permitir a estas personas que curen sus heridas, vuelvan a ser personas sanas y retomen el camino junto a toda la comunidad eclesial. La misericordia de Dios no provee una cobertura temporal de nuestro mal, al contrario, abre radicalmente la vida a la reconciliación, dándole nueva confianza y serenidad, mediante una auténtica renovación. La pastoral familiar, lejos de cerrarse en una mirada legalista, tiene la misión de recordar la gran vocación al amor a la que la persona está llamada, y de ayudarla a vivir a la altura de su dignidad» (n. 80).

Subrayo de este número dos ideas centrales. Primero, que el Sínodo no puede quedarse en una mera especulación teológica que no aterrice con respuestas a problemas vitales, como ejercicio de una Iglesia samaritana que se acerca al caído en la cuneta: «La verdadera urgencia pastoral es permitir a estas personas 
que curen sus heridas, vuelvan a ser personas sanas y retomen el camino junto a toda la comunidad eclesial». Segundo, el reclamo de una Pastoral Familiar renovada, en la que la Iglesia tiene mucho camino hecho, conscientes de que en la familia nos lo jugamos todo: el futuro de la sociedad y la trasmisión de la fe: «La pastoral familiar, lejos de cerrarse en una mirada legalista, tiene la misión de recordar la gran vocación al amor a la que la persona está llamada, y de ayudarla a vivir a la altura de su dignidad».

Cierta información ha trasmitido la sensación de que los trabajos del Sínodo se han centrado, casi con exclusividad, en estos puntos conflictivos. Esta tendencia no ha prestado un buen servicio. Las expectativas se centraron en la espera de respuestas rápidas y normativas que permitan tal o cual cosa. Es peligroso aterrizar en concreciones normativas sin haber levantado el vuelo a una reflexión madura. Esto ha condicionado la lectura desde fuera del Sínodo y posiblemente ha causado confusión y hasta dolor en algunos.

b) Unas consideraciones concretas al hilo de los diversos documentos sinodales

La misma mecánica del desarrollo del Sínodo favorece una reflexión progresiva que va delimitando los temas y focalizando los puntos que necesitan mayor estudio. No es, pues, un fracaso que en este primer Sínodo Extraordinario se hayan abierto más expectativas que resuelto preguntas concretas. Es ésta, quizás, la pretensión del Papa con la convocatoria de dos sesiones, una Extraordinaria y otra Ordinaria: abrir el abanico de temas, para, despés de un tiempo de reflexión, y de oración, cerrar armónicamente el debate con unas directrices doctrinales y concreciones pastorales. Estamos a mitad de un camino esperanzador.

La «Relación Final» presentada al Papa, y que se ha hecho pública con los resultados de la votación, recoge los trabajos del Sínodo en 62 propuestas. Después de haber sido estudiadas en los círculos menores, grupos de trabajo por lenguas, aportados los modos y sugerencias, han sido votadas en la Asamblea sinodal. No debe extrañar que haya más consenso en unas proposiciones que en otras. Hubiera sido estéril y frustrante una uniformidad de pensamiento en temas que requieren reflexión y diálogo. Los padres sinodales no fueron convocados al aula sinodal a confesar la fe -confesión que proclamaron junto al sucesor de Pedro en las diversas celebraciones, especialmente en las de apertura y clausura- sino a enriquecer con la reflexión y el diálogo la exposición de la misma y la concreción en los comportamientos de los creyentes. El juego de pareceres es fruto de la libertad y valentía, adornada de humildad, que reclamaba el Papa para los trabajos sinodales. Se pueden proponer estas primeras apreciaciones generales:

1. Un gran consenso en lo esencial, ha presidido los trabajos del Sínodo. Lo que se ha llamado «la desestructuración del tríptico fundamental de la Creación: matrimonio, familia y vida» en la sociedad actual es, quizás, la gran preocupa- 
ción de la Iglesia. El análisis de la situación de la familia en medio del mundo, la toma de conciencia de la problemática que atraviesa y el gran desafío pastoral que plantea a la Iglesia, es la temática expuesta en la Introducción y Primera Parte de la Relación Final. Fue aprobaba casi por unanimidad.

La prolífica reflexión sobre el matrimonio y la familia, iniciada después del Concilio Vaticano II, nos ofrece una rica exposición de la doctrina sobre el sacramento del matrimonio y sobre la espiritualidad esponsal y familiar. No hay disensos dogmáticos en lo esencial. El punto de debate se centrará en como configurar en una normativa concreta los grandes principios. Subrayaría de esta parte de la Relación unas palabras programáticas: «El cambio antropológico-cultural influye hoy en día en todos los aspectos de la vida, y exige un enfoque analítico y diversificado» (Relación Final, n. 5). La visión antropológica de fondo, con distintas escuelas y tendencias, tiene una repercusión relevante en los posibles enfoques morales que deben orientar la normativa más específica. Es un tema de debate que necesita serena reflexión.

Es interesante resaltar, también, la importancia que se ha dado a la vida afectiva: «En el mundo actual no faltan tendencias culturales que parecen imponer una afectividad sin límites, de la que se quieren explorar todas las vertientes, incluso las más complejas. De hecho, la cuestión de la fragilidad afectiva es de gran actualidad: una afectividad narcisista, inestable y cambiante que no ayuda siempre a los individuos a alcanzar una madurez mayor... En este contexto, las parejas están a menudo perplejas, titubean y les cuesta encontrar la forma de crecer. Son muchos los que tienden a permanecer en las etapas primarias de la vida emocional y sexual. La crisis de la pareja desestabiliza a la familia, y, a través de las separaciones y de los divorcios, puede llegar a acarrear graves consecuencias a los adultos, a los hijos y a la sociedad, debilitando al individuo y los lazos sociales» (Relación final n. 10). Esta reflexión abre un punto de inflexión que cuestiona si estamos preparando adecuadamente para la vida matrimonial y familiar.

Se subraya la dimensión pastoral del Sínodo. Se pueden considerar como una declaración de principios general, las siguientes palabras: «Los grandes valores del matrimonio y de la familia cristiana se corresponden con la búsqueda que caracteriza a la existencia humana, incluso en un tiempo marcado por el individualismo y por el hedonismo. Es preciso acoger a las personas con su existencia concreta, saber sustentar su búsqueda, alentar el deseo de Dios y la voluntad de sentirse plenamente parte de la Iglesia incluso en quien ha experimentado el fracaso o se encuentra en las situaciones más diversas. El mensaje cristiano lleva siempre en sí la realidad y el dinamismo de la misericordia y de la verdad, que convergen en Cristo» (Relación Final, 11).

2. La verdad y la belleza de la familia: sus gozos y sus heridas. La Segunda Parte de la Relación Final, trata sobre el Evangelio de la Familia. En ella, se mantiene el consenso general en temas de doctrina y principios. Así, se subraya en dos apartados: «la familia en el designio salvífico de Dios» y «la familia en los 
documentos de la Iglesia». En estos dos aspectos, la riqueza de la reflexión desde el Concilio Vaticano II (señalamos: Lumen Gentium, n. 11; Gaudium et spes nn. 47-52), se ha vista enriquecida por el magisterio de Pablo VI (sobre todo, la encíclica Humane vitae), de Juan Pablo II (sobre todo, la Exhortación Familiaris consortio y sus ricas catequesis sobre el amor humano, de cuya interpretación y desarrollo conviene ampliar la reflexión) y de Benedicto XVI (primordialmente, en Deus Caritas est). El Concilio y el magisterio posterior han suscitado un bagaje teológico muy rico, que está teniendo un lento aterrizaje pastoral en el campo de la preparación al matrimonio y la vida familiar.

En el apartado titulado «la indisolubilidad del matrimonio y la alegría de vivir juntos», hay un primer punto de cierta disensión (el diccionario de la RAE define la disensión: «oposición o contrariedad de varios sujetos en los pareceres o en los propósitos»). La propuesta 22, recaba 160 «sí», y 22 «no». Dice así:

En esta misma perspectiva, haciendo nuestra la enseñanza del Apóstol según la cual toda la creación fue concebida en Cristo y con vistas a él (cf. Col 1, 16), el Concilio Vaticano II quiso expresar aprecio por el matrimonio natural y por los elementos válidos presentes en las demás religiones (cf. Nostra ætate, n. 2) y en las culturas, pese a sus límites e insuficiencias (cf. Redemptoris missio, n. 55). La presencia de las semina Verbi en las culturas (cf. Ad gentes, n. 11) podría aplicarse, en algunos aspectos, también a la realidad matrimonial y familiar de tantas culturas y de personas no cristianas. Existen, pues, elementos válidos también en algunas formas ajenas al matrimonio cristiano -basado, en cualquier caso, en la relación estable y verdadera entre un hombre y una mujer-, que en todo caso consideramos que están orientadas hacia él. Con la mirada puesta en la sabiduría humana de los pueblos y de las culturas, la Iglesia reconoce también esa familia como célula básica necesaria y fecunda de la convivencia humana.

Este cierto disenso, con este trasfondo, reaparecerá en los nn. 41 y 42 de la Relación Final.

Es éste un punto que puede abrir cauces de reflexión para iluminar propuestas pastorales que respondan a la problemática de las parejas de hecho, las convivencias antes del matrimonio, el mismo matrimonio civil. Pensemos que en muchos países el matrimonio civil precede al sacramento y no es alternativo, como en España. El tema de la "gradualidad de la ley», (que aparece en la Relación post Disceptacionem y que desaparece después, y se suple con una propuesta pedagógica) rectamente entendida, puede iluminar este aspecto. La reflexión de la Teología moral, en toda su amplitud y más allá de enquistamientos de escuela, debe prestar un gran servicio para concretar la reflexión teológica sobre la verdad intangible del Dogma con respuestas pastorales apropiadas.

En el apartado siguiente, titulado «la verdad y belleza de la familia y la misericordia sobre las familias heridas y débiles», se abre en el Sínodo una cierta discrepancia que florecerá en varios números subsiguientes. Habiendo existido un consenso general en los principios, el debate está centrado sobre todo en 
la atención pastoral a las personas en «situación irregular». En concreto, en el n. 25 de la Relación, se dice: "Con vistas a un acercamiento pastoral a las personas que han contraído matrimonio civil, a las que están divorciadas y se han vuelto a casar, o a las que simplemente conviven, corresponde a la Iglesia revelarles la divina pedagogía de la gracia en sus vidas y ayudarlas a alcanzar la plenitud del plan de Dios en ellas. Siguiendo la mirada de Cristo, cuya luz alumbra a todo hombre (cf. Jn 1, 9; Gaudium et spes, n. 22), la Iglesia se vuelve con amor hacia quienes participan en su vida de manera incompleta, reconociendo que la gracia de Dios actúa también en sus vidas, dándoles el valor necesario para hacer el bien, para cuidar con amor uno de otro y para estar al servicio de la comunidad en la que viven y trabajan». Los 39 «no» concedidos a esta proposición, frente a 140 «sí», reflejan ya una toma de postura que se va a mantener, en dos aspectos concretos, a lo largo de la votación de las conclusiones. Así se refleja en las proposiciones 27 (sobre la atención a los matrimonios civiles y las convivencias: 147 «si», 34 «no») y la 28 (sobre la atención a los matrimonios heridos y rotos: 152 «si», 27 «no»). Igualmente en las proposiciones 41 y 42 , que comentaremos más adelante.

Quizás, en un grupo de sinodales existía un cierto resquemor de que la aceptación de una determinada práctica pastoral pudiera cambiar los principios doctrinales. Una lectura de las parábolas de la misericordia, nos puede ayudar a resaltar «la acción misionera y evangelizadora» de la mano tendida: la búsqueda de la oveja perdida, el abrazo al hijo pródigo, han devuelto a muchos a una vida más familiar y al calor del amor del Padre. Y el perdón a la pecadora y la atención del buen samaritano al expoliado en la cuneta, han devuelto a la posada de la iglesia a hijos marginales. Con el bálsamo de la misericordia, la Iglesia, el Evangelio y la imagen de Dios, siempre quedan fortalecidos.

\section{c) Perspectivas pastorales: puntos de debate}

La Tercera parte aborda las perspectivas pastorales. Se inicia con un apartado dedicado a «anunciar el Evangelio en los diversos contextos culturales». Esta parte descriptiva de la realidad recibió un consenso casi general. Siguen dos apartados dedicados a «la preparación al matrimonio y la atención a los primeros años de casados», que concitan casi la unanimidad (Proposiciones 39 y 40).

En el apartado sobre «atención pastoral de los que viven en el matrimonio civil o en convivencias», crece la discrepancia. Así, la proposición 41 (125 «sí», 54 «no»): «Al tiempo que sigue anunciando y promoviendo el matrimonio cristiano, el Sínodo alienta también el discernimiento pastoral de las situaciones de tantos que no viven ya esta realidad. Importa entablar un diálogo pastoral con estas personas, con el fin de poner de relieve los elementos de su vida que puedan conducir a una mayor apertura al Evangelio del matrimonio en su plenitud. Los pastores han de identificar elementos que puedan favorecer la evangelización y el crecimiento humano y espiritual. Una sensibilidad nueva de la pastoral actual consiste 
en captar los elementos positivos presentes en los matrimonios civiles y, con las debidas diferencias, en las convivencias. Es preciso que en la propuesta cristiana, aun afirmando con claridad el mensaje cristiano, señalemos también elementos constructivos en aquellas situaciones que no se corresponden aún o no del todo con él». Más consenso recibe la propuesta 42 (37 «no»), que explicita la anterior.

En el apartado «curar las familias heridas», las discrepancias aumentan: respecto a simplificar y abreviar los procesos de nulidad (Proposición 48: 143 «si», 35 «no»; que se explicita también en la proposición 49); sobre la posibilidad de que los divorciados y vueltos a casar accedan a los Sacramentos (Proposición 52: 104 «sí», 74 «no»; proposición 53: 112 «sí», 64 «no») y la atención pastoral a las personas con orientación homosexual (Proposición 55: 118 «sí», 62 «no»).

Se concluye con los temas de la transmisión de la vida y el desafío del descenso de la natalidad, el desafío de la educación y el papel de la familia en la evangelización. El consenso es general.

Resumiendo: sólo tres proposiciones no alcanzaron los dos tercios. Se refieren a dos temas concretos: «sobre la posibilidad de que personas divorciadas y vueltas a casar se acerquen a los Sacramentos» (la Proposición 52, con 74 «no», y la 53, con 64 «no») y «sobre la atención pastoral a las personas con orientación homosexual» (Proposición 55, con 62 «no»). Si el sínodo paralelo, orquestado por la liturgia mediática, reducía la propuesta sinodal a estos dos puntos, el debate en el aula sinodal ha puesto de relieve que es el nudo gordiano del consenso. Pero el error sería el atrincheramiento en las decisiones normativas y pastorales ya definidas. Es la hora de levantar el vuelo de la reflexión teológica, dialogando entre las corrientes de pensamiento en antropología y moral, que vuelven a aflorar. Y buscar, en una exégesis bíblica en su conjunto con especial atención a san Pablo, experto en comunidades, cauces de consenso, desde dos coordenadas que han orientado el Sínodo: la verdad y la misericordia.

El tiempo que se abre hasta el nuevo Sínodo no puede gastarse, malgastarse según mi opinión, en reflexionar desde posturas tomadas, buscando reforzar las mismas con una lluvia de documentos. Hay que dialogar desde la profundidad de la reflexión para buscar los puntos de consenso que enriquezcan las respuestas urgidas por lo cotidiano de la práctica pastoral.

\section{Propuestas de REFleXión PARA unA PROPUESTA PAStoral}

Después de esta mirada general al Sínodo, a través de sus documentos, me propongo delinear una serie de inquietudes pastorales que tocan, algunas en su raíz y otras tangencialmente, la reflexión del Sínodo.

Comenzaré, como párroco, con una mirada realista al «entorno» (la realidad pastoral de una parroquia: sus demandas y búsqueda de respuestas) que envuelve mi parroquia y que reclama de mí una respuesta pastoral. Sugiero algunas propuestas, desde la perspectiva de la familia, que aviven la reflexión. 


\section{Con humildad, aceptar «un cierto fracaso pastoral»}

Desde el punto de mira de la familia, ha bajado clamorosamente el porcentaje de matrimonios que sellan su compromiso con el sacramento; la curva indicativa de divorcios o separaciones entre los que lo han recibido se ha disparado; crece, con un silencio cómplice de resignación, la dramática indiferencia de un alto número de jóvenes ante el mismo hecho del matrimonio -religioso o meramente civil- que optan, o simplemente se dejan arrastrar, por unas uniones de hecho. En muchos de estos jóvenes, no hay agresividad ante la misma institución matrimonial sino simplemente indiferencia. Incluso, en algunos de ellos, hay un cierto rescoldo de fe. ¿Cómo explicar estos hechos incontestables?

Esta radiografía sociológica, quizás simplista, nos pone frente a un problema pastoral de magnitud: aceptar un cierto fracaso en nuestra pastoral en general y en concreto en la Pastoral Familia: ¿por qué no hemos sabido transmitir la belleza del matrimonio y la fuerza de la gracia del sacramento a las nuevas generaciones? ¿Qué ha fallado en el acompañamiento de la vida matrimonial y familiar de aquellos que recibieron la gracia del sacramento ante la atenta mirada del sacerdote o diácono, representes de la Madre Iglesia? ¿Por qué hemos quedado perplejos ante las nuevas situaciones que han afectado al matrimonio y la familia y no hemos sabido reaccionar con propuestas creativas y no meramente defensivas?

Después de mirar los estudios sociológicos sobre la situación de la familia y leer las respuestas sobre la "consulta previa» a la celebración del Sínodo, y algunas opiniones expresadas en la misma asamblea, podemos afirmar, sin derrotismo pero también con realismo, que la Pastoral Familiar no ha levantado vuelo. Limitada, en la mayoría de los casos, a los tradicionales «cursillos prematrimoniales», no ha ofrecido un renovado planteamiento acorde con las circunstancias actuales en las que viven los novios, las distintas visiones del matrimonio que se ofertan y las alternativas a la familia que se difunden.

Contamos con bellos documentos. Ha sido rico el magisterio de Juan Pablo II desde la Exhortación postsinodal Familiaris consortio. Para Benedicto XVI el tema de la familia era recurrente y angular en su diagnóstico sobre la situación religiosa y en la estrategia pastoral requerida. En concreto, en España hay dos documentos de la Conferencia Episcopal (La familia, santuario de la vida y esperanza de la sociedad, Madrid 2001; Directorio de la Pastoral Familiar de la Iglesia de España, Madrid 2003) ricos en pensamiento. Sin embargo, no han recibido una recepción adecuada, en su estudio en las diócesis, que diera origen a planteamientos pastorales renovados y atrevidos. $\mathrm{O}$ si se han ofrecido, no se han apoyado en una adecuada estrategia y valentía pastoral que cambie hábitos y vicios pastorales obsoletos. No ha habido en general un aterrizaje en la pastoral ordinaria. Hemos oído poco hablar, con entusiasmo, de una Pastoral Familiar renovada. $Y$ a veces, los entusiasmos han sido más pasionales que pastorales, produciendo un cierto efecto rechazo. 
Aceptar este cierto fracaso nos puede hacer más humildes y cambiar algunas actitudes revestidas de falsa seguridad defensiva. $Y$ la humildad nos puede poner en la senda de la verdad, para reafirmar el valor del sacramento, predicar con entusiasmo su gracia y, a la vez, buscar en la misericordia cauces creíbles de respuesta a situaciones vitales que, todavía, lo reclaman.

Pongamos un ejemplo: ante la discusión sobre el acercamiento o no a la Eucaristía por parte de los divorciados, nos hemos quedado en debates sobre el sí y el no. Sin duda son necesarios, pero quizás hemos pasado de largo sobre una realidad hermosa: jalgunos quieren acercarse! Por eso, hay debate. Lo dramáti$\mathrm{co}$, es que se hubiesen diluido en la indiferencia o el abandono: ¡Quieren volver! O sea, que hay parábola: ¡Sí, me levantaré y volveré junto a mi Padre! ¿Qué hubiese sido de la parábola si el hijo pródigo se hubiera recreado en su trabajo, alimentándose de las bellotas de los cerdos, sin añorar la casa del Padre? Hoy, la Iglesia, como ha señalado el Papa Francisco en el discurso de clausura del Sínodo tiene que «derramar aceite y vino sobre las heridas de los hombres».

Las parábolas de la misericordia nos ofrecen el guión para una respuesta pastoral que hoy tiene que ser pedagógicamente progresiva. Conjugando tres verbos: acoger (a la comunión «eclesial»), discernir (con verdad y misericordia), acompañar (como proceso).

\section{Un profundo "giro antropológico» condiciona la Pastoral Familiar}

Es urgente tomar el pulso a la vida del matrimonio y la familia, que vive en un «entorno cambiante, quizás de vértigo». Las parejas que nos vienen hoy a solicitar el sacramento vienen de un entorno agresivo a la misma realidad del matrimonio y la familia. Y son fruto de una generación peculiar que reviste la fragilidad moderna de la estructura humana: la incapacidad para adquirir compromisos, el miedo a la perdurabilidad y la exaltación de lo provisional. Todo ello, está en el ambiente como condicionamiento previo a cualquier opción de fe.

La cuestión antropológica es un preámbulo no meramente académico, sino profundamente existencial. Podríamos proponer como tesis que la estructura antropológica del hombre moderno muestra cierta resistencia a dos claves fundamentales para la esencia del matrimonio cristiano: la «exclusividad» y el «para siempre». En este caldo de cultivo, se inserta la realidad salvífica del sacramento del matrimonio. En la actualidad, ha cambiado tanto el entorno en el que tiene que vivir un matrimonio que se necesita, más que nunca, reforzar la identidad antropológica como base del mismo sacramento para que no se diluya en unas corrientes de pensamiento que no lo entienden: ¿por qué «para siempre»?

El debate llega, hoy, a una profundidad más oscura: ¿sólo un tipo de matrimonio? La «ideología de género» ha sido más viva y astuta en difundir su doctrina que nuestra apología en rebatirla, venida casi siempre desde el ámbito eclesiástico. Y además ésta, no ha sabido acomodar su lenguaje ni buscar aliados en otros campos de la misma ciencia y el pensamiento. Nuestra propuesta cristiana 
ha sido arrollada. En principio, podemos proponer otra tesis: hasta hace poco, cuando hablábamos de matrimonio, estaba bien definido el concepto -incluso en el diccionario: entre un hombre y una mujer-y se daba por sentado que requería una aspiración, al menos, a que fuera en «exclusividad» y para «siempre». Hoy el concepto, denominado intencionadamente como «tradicional», ha saltado por los aíres, al son de una amplia orquesta que sugiere alternativas.

Esta realidad hay que tenerla en cuenta a la hora de hablar de preparación al matrimonio y la vida familiar. El tema antropológico es la introducción necesaria a cualquier propuesta. Si se trata de hablar del matrimonio y de la familia, conviene comenzar por hablar de lo previo al matrimonio: de las circunstancias en las que acuden quienes lo demandan, en las concepciones desvirtuadas que flotan en el ambiente, en una cierta resignación inicial de que "esto es muy difícil», y que «dura lo que dura». Junto a la confusión antropológica, es necesario considerar también la debilidad de la fe de muchas parejas que acuden a solicitar el sacramento. Algunas de estas circunstancias, las planteaba Benedicto XVI como cuestión a aportar para la reflexión sobre la posible nulidad del matrimonio (Discurso al Tribunal de la Rota romana, el 26 de enero de 2013).

Decía alguien que «el mundo se mueve a ritmo del lince, mientras la Iglesia camina con la parsimonia de un elefante». Los temas específicos de la pastoral, entre ellos la preparación al matrimonio y a la vida familiar, necesitan ser repensados, concluyendo en unas estrategias pastorales nuevas, partiendo de un profundo análisis de la situación en la que viven las parejas que se acercan, muchas con cierto temor y otras con una pizca de inconsciencia, a solicitar el sacramento del matrimonio.

No vendría mal, después de la Asamblea extraordinaria, colaborar en una reflexión que abra dos puertas de par en par: la puerta de una propuesta de Pastoral Familiar renovada, lejos del claroscuro y teñida de color, que afiance la belleza del matrimonio y la familia, exponiendo el esplendor de la verdad de la misma. Pero, también debemos abrir la puerta de la misericordia, buscando las respuestas adecuadas para atender, con valentía y creatividad, las situaciones dolorosas que nos rodean en la pastoral diaria de nuestras parroquias.

El papa Francisco nos interpela en Evangelii gaudium. Nos urge a salir a las periferias, que no consisten en zonas geográficas. No podemos caer en la tentación de una «pastoral para los buenos». La misión hoy nos espera a las puertas de casa; los excluidos pueden pertenecer a nuestra propia familia.

\section{Una interpelación: «ante tanto cambio ¿debemos seguir haciendo lo mismo?»}

Una tarea de este período inter-sinodal será abrir la mirada a un planteamiento global de la pastoral de la iglesia, que debe recaer sobre la clave de la familia. Nos vamos a fijar en tres campos de la pastoral: La Iniciación Cristiana, la Pastoral Juvenil y la Preparación al Matrimonio. 
a) La Iniciación Cristiana. Permitidme de inicio una cierta «caricatura» de la pastoral de una Parroquia. En cualquier Parroquia, las prioridades pastorales, contabilizadas en tiempo, pueden dar estas proporciones: dos reuniones para celebrar un Bautismo solicitado, cada vez más, por padres no casados o divorciados vueltos a casar. Incluso se reclama a los padrinos un certificado de Confirmación. Y yo me pregunto: ¿certifica este papel una vida cristiana adulta para acompañar a un neófito? Siguen tres años de reuniones semanales para preparar la Primera Comunión, en ocasiones se administra previamente el sacramento de la Confirmación. Pero los padres que asisten a estos sacramentos que completan la Iniciación Cristiana, son los mismos que solicitaron el Bautismo. En general, no ha habido una pastoral con los padres ni se han sentido interpelados ni han cambiado su actitud respecto de la educación cristiana de sus hijos. El esfuerzo pastoral se ha centrado en los niños. La mayoría de los niños, completada su Iniciación Cristiana y con la vitola de «cristianos adultos», abandonan los cauces formativos a los nueve años. Pensemos que no es lo mismo hablar de Iniciación cristiana en ambiente favorable y creyente que en un hábitat neopagano, pero con costumbres, simplemente costumbres, cristianas. La Iniciación Cristiana es un tema decisivo en la pastoral misionera. No conviene enredarnos en opiniones y prácticas diversas que crean, a veces, más confusión que comunión.

b) La Pastoral Juvenil. También suele haber en todas las parroquias grupos de jóvenes, aunque sean minoritarios. Este campo suele producir mucha frustración e impotencia: tenemos pocos jóvenes y a menudo no sabemos qué hacer con ellos. La Pastoral Juvenil lleva demasiado tiempo con ensayos que intentan una segunda síntesis de fe o asegurar unos contenidos del credo, pero sin analizar la problemática de fondo. Detrás de cada joven hay una familia y ésta configura cada vez menos, ya que la educación hoy no es eminentemente prefigurativa (de padres a hijos) sino sustancialmente configurativa (ambiente, grupo de amigos, entorno cultural) y son frecuentes las familias desestructuradas.

El cambio de generaciones no se da ya en cada década sino en cada quinquenio: nueva mentalidad más emocional que discursiva, nueva percepción que no conecta con el discurso racional sino con la experiencia vivida; nuevo ambiente neopagano envolvente. Los contenidos catequéticos no se trasmiten por el vehículo del discurso sino que se descubren desde las experiencias compartidas y la configuración con testigos atrayentes. Es curioso, también, la ausencia del contenido explícito de la moral cristiana en la catequesis juvenil. Se rehúye. Sin embargo, en esta etapa juvenil se inicia la «preparación remota» al matrimonio.

La exigencia del grupo, de la comunidad, es urgente para una acción pastoral con jóvenes. En muchas parroquias es tal la pobreza que no puede darse. Estimo que la Pastoral Juvenil debe romper el círculo de lo parroquial y lanzarse en un movimiento comunitario de ámbito diocesano. Analizar la experiencia de los Encuentros Mundiales de la Juventud o el eco de Taizé o las peregrinaciones a Santiago, puede ser revelador. 
c) La Preparación al Matrimonio y la Vida Familiar. Y llegamos a la petición del matrimonio. Los novios se acercan a la parroquia a pedir el sacramento. La mayoría dejó su formación, celebrada su Primera Comunión. Y ahora, se acercan a pedir otro sacramento, del que no saben ni siquiera que son sus ministros. Por lo regular se está más atento a lo burocrático: fecha, hora, expediente, sin una auténtica acogida. Se ofrecen un cursillo, de más o menos duración. Pero ¿quiénes vienen a solicitar el Sacramento?: suelen ser jóvenes en tono a los treinta años; muchos, con un trabajo inestable; constatamos que son cada vez más frecuentes las parejas que un largo noviazgo le ha impulsado a vivir juntos.

Las motivaciones que les mueven a pedir el sacramento son variopintas: en un grupo, es fruto de una fe vivida; en muchos, es simplemente un rescoldo de una fe y tradición familiar; otros, simplemente la costumbre y el reclamo de una ceremonia más bella. Solemos meterlos a todos en el mismo cursillo. Por supuesto, una vez celebrado el sacramento, no suele haber un proyecto de seguimiento de los nuevos esposos y de formación adecuada a su nuevo estado.

Hay muchas intuiciones, en documentos ricos del Magisterio universal y de nuestra Conferencia Episcopal, que necesitan ser concretadas y aterrizadas en la pastoral cotidiana. Pero con proyecto y constancia, con una mirada larga y empleando las personas y medios necesarios. Uno de los grandes desafíos de la pastoral es marcar hoy las dos o tres auténticas prioridades. El eje de la Pastoral Familiar debe dar unidad y continuidad y, a la vez, abrir el abanico de los distintos sectores pastorales: Iniciación Cristiana, Pastoral Juvenil, Pastoral matrimonial.

\section{Pablo nos ofrece un estilo y talante pastoral de suma actualidad}

Pablo es maestro de comunidades. Nadie como él tuvo que responder a los desafíos de la inculturación de la nueva fe en un entorno adverso. Pablo dejó el rescoldo judío para injertar la fe en el Resucitado en el frío hábitat del paganismo. Quizás hoy también, especialmente en el primer mundo, debamos volver a sembrar la semilla de la fe en un terreno baldío que podemos calificar como «neopagano». Benedicto XVI nos ha dejado hondas reflexiones sobre este tema.

Lamentablemente, a veces nos falta fijar la mirada en aquellos a quienes nos dirigimos: no sólo hablamos a personas que peregrinan apoyados en el bastón de la fe; hay otros caídos en el camino a los que se les ha quebrado el apoyo y que se acercan a la Iglesia renqueantes, como peregrinos esporádicos, buscando sentido a sus vidas en declive; y hay muchos más que vienen de territorio pagano, de nuestros propios barrios: «han oído hablar de Dios, pero no le han visto sus ojos» (cf. Job 42,5-6), fueron bautizados, pero viven «como si Dios no existiera». Existen, y valga la paradoja, «bautizados paganos». Es novedoso y debemos preguntarnos: ¿cómo llegar a ellos, cómo responder a sus demandas?

Quizás estamos bien preparados para acompañar la fe de los mejores, alentar la fe de los débiles, pero nos sentimos desvalidos para «implantar la fe» donde se 
perdió o donde no la hubo. A la Iglesia le cuesta «ser misionera». La recepción de Evangelii gaudium, sin lecturas fáciles ni componendas, nos empuja a cambios profundos de pensamiento, pastoral y estructuras. ¿Estamos dispuestos? Se ha roto la uniformidad de aquellos a los que nos dirigimos. Antes era fácil: creyentes y no creyentes. Hoy, hay un amplio abanico de receptores del mensaje y necesitan propuestas y estrategias pastorales nuevas. Necesitamos una reflexión serena y realista, fuera de las trincheras de pensamiento y de posturas de grupo.

Pablo, que convivió con tendencias divergentes en los primeros años de la implantación de la fe, nos sirve de guía y maestro. Él es maestro de la fe y experto en comunidades. Su evangelización venía urgida por la situación de aquellos a los que predicaba, distintos de los creyentes de Jerusalén. Tuvo que confirmar con Pedro la autenticidad de su doctrina ante las acusaciones de quienes se consideraban portadores exclusivos de la verdad. La confluencia de Santiago y Pablo junto a Pedro es un paradigma para hoy. No es una imagen forzada ver a Francisco, como Pedro, atrayendo a los seguidores de Santiago desde la seguridad de la sinagoga, y a los neófitos de Pablo desde la dispersión. A todos nos interpela el mismo grito: «jay de mí si no evangelizare!» (1 Cor 9,16).

En la estela de Pablo, no vendría mal releer la Primera Carta a los Corintios. La relación del apóstol con esta comunidad puede constituirse en un cierto paradigma misionero para nuestro tiempo. El apóstol escribió diversas cartas a esta comunidad viva e inquieta que le trajo sufrimientos y alegrías; la visitó personalmente varias veces, tuvo que enviarles mensajeros como Timoteo o Tito y, al parecer, existió una tercera carta especialmente dura, la llamada «carta de las lágrimas» (cf. 2 Cor 2,3s.9; 7,9.12). En la Primera Carta, el tema de la unidad y la confrontación con Apolo (Cf. 1 Cor 1, 10-17) abre la primera sección catequética. Pablo recurre a un genérico «cada cual anda diciendo» (1 Cor 1,12) para afrontar este tema de la comunión. Después, con un «se oye decir en todas partes...» (1 Cor 5,1), aborda tres temas candentes: el incesto, el recurso a los tribunales civiles, la prostitución. Constatamos que las respuestas del apóstol van dirigidas a cuestiones vivas. En el capítulo 7, el apóstol trata temas planteados por la misma comunidad, esta vez por escrito: «acerca de lo que habéis escrito, es bueno que...» (1Cor 7,1). La temática es sobre el matrimonio y el apóstol reflexiona doctrinalmente y aconseja pastoralmente. Una exégesis adecuada de este pasaje nos puede dar luz doctrinal y talante pastoral.

La moral de Pablo, moral en dos tiempos: indicativo e imperativo, debe volver a nuestra estrategia pastoral. Pablo reclama una peculiaridad en los comportamientos morales de los nuevos cristianos, diferenciados de los paganos (es hermosa su catequesis sobre la cuestión planteada: «¿es lícito comer la carne sacrificada a los ídolos?», cf. 1 Cor 8; y la siguiente apelación a su propio ejemplo: «¿No soy libre? ¿No soy apóstol?». cf. 1 Cor 9). Pero, con sabia pedagogía no les expone sólo el imperativo de lo mandado, previamente ha indicado con entusiasmo y convicción la belleza de lo que somos: Cuerpo de Cristo, templos 
del Espíritu. De la gracia de lo que somos fluye la fuerza para hacer lo que debemos. Hoy, a muchos de los que nos rodean aún no se les ha mostrado o no han descubierto la belleza de la vocación a la que han sido llamados, por tanto es estéril reclamar ciertos comportamientos.

El Mensaje final de los padres sinodales se centra en esta clave paulina: consolación y exhortación. No es sólo dulzura. La exhortación paulina tiene mucho de invitación a la conversión, de reclamo de coherencia, de exigencia de vivir a la altura de lo que somos. El lenguaje de Pablo es hoy de gran actualidad.

El Catecismo de la Iglesia Católica, en su interna armonía pedagógica y pastoral no se inicia con la tercera parte, dedicada a la moral. Se abre con una confesión de fe, recogida en el Credo, que nos indica nuestra condición de hijos de Dios. Se continúa en la celebración gozosa de los sacramentos. Y entonces, sólo entonces, plantea toda la exigencia de la moral cristina, para «caminar a la altura de la vocación recibida». La cuarta parte, dedicada a la oración, nos presenta la necesidad de tratar con Dios, de orar, para ser y vivir en cristiano.

Queda ahora un largo camino para los expertos. No para afianzar posturas, sino para abrir caminos. Se necesitan propuestas fundadas en la verdad y la misericordia, sabiendo que la verdad sin misericordia puede ser «injusta», pero también puede serlo la misericordia sin verdad, sobre todo si se adorna de demagogia. Se ha generado una gran expectativa. Esforcémonos todos en no obstaculizar al Espíritu. Podríamos quemar un último cartucho en un tema tan relevante como la familia, en la que se juega el futuro de la sociedad y la Iglesia.

\section{Y rezar juntos}

Hay una actitud que que crea comunión y desbroza caminos: orar juntos. Recogemos las palabras finales del Mensaje de los padres sinodales:

Nosotros, los Padres Sinodales, pedimos que caminen con nosotros hacia el próximo Sínodo. Entre ustedes late la presencia de la familia de Jesús, María y José en su modesta casa. También nosotros, uniéndonos a la familia de Nazaret, elevamos, al Padre de todos, nuestra invocación por las familias de la tierra:

Padre, regala a todas las familias la presencia de esposos fuertes y sabios, que sean manantial de una familia libre y unida. Padre, da a los padres una casa para vivir en paz con su familia. Padre, concede a los hijos que sean signos de confianza y de esperanza y a los jóvenes el coraje del compromiso estable y fiel. Padre, ayuda a todos a poder ganar el pan con sus propias manos, a gustar la serenidad del espíritu y a mantener viva la llama de la fe también en tiempos de oscuridad. Padre, danos la alegría de ver florecer una Iglesia cada vez más fiel y creíble, una ciudad justa y humana, un mundo que ame la verdad, la justicia y la misericordia. 